\title{
ECONOMIA DO COMPARTILHAMENTO, ASSIMETRIA INFORMACIONAL E REGULAÇÃO ECONÔMICA CONSUMERISTA
}

\author{
SHARING ECONOMY, INFORMATIONAL ASYMMETRY, AND ECONOMIC \\ CONSUMER REGULATION
}

\author{
${ }^{1}$ João Victor Ruiz Martins \\ ${ }^{2}$ Marcia Carla Pereira Ribeiro
}

\section{RESUMO}

$\mathrm{O}$ artigo analisa de que maneira os aplicativos que atuam com base na economia do compartilhamento reduzem os custos e transação entre seus usuários e afetam a necessidade de regulação em defesa do consumidor. Relata as contribuições de Akerlof, Spence e Stiglitz para a formação da economia da informação e os problemas econômicos decorrentes da assimetria informacional. Expõe a atuação do Estado para a resolução das assimetrias por meio da atuação regulatória, os mecanismos de reputação utilizados pela economia do compartilhamento e suas consequências para uma eventual regulação do setor, na perspectiva da defesa do consumidor.

Palavras-chave: Direito; Economia; Desenvolvimento; Eficiência; Economia do Compartilhamento.

\begin{abstract}
This article examines how the applications that operate based on the sharing economy reduce transaction costs among its users, and how this affects their need for regulation on consumer protection. This article discusses the contributions of Akerlof, Spence e Stiglitz to the formation of the information economy and the economic problems arising from information asymmetry. Then it discusses the role of the State on the resolution of informational asymmetries. Finally, it discusses the reputation mechanisms used by the sharing economy to reduce information asymmetry and what are its consequences for economic regulation, on consumer protection perspective.
\end{abstract}

Keywords: Law; Economics; Development; Efficiency; Sharing Economy.

\footnotetext{
${ }^{1}$ Mestrando e Bacharel em Direito pela Universidade Federal do Paraná (UFPR), Curitiba, Paraná, Brasil. Email: ruizmartins@gmail.com

${ }^{2}$ Pós-doutorado em direito pela Universidade de Lisboa (ULISBOA),Lisboa, Portugal. Mestre em direito pela Universidade Federal do Paraná (UFPR), Curitiba, Paraná, Brasil. Professora Associada na Universidade Federal do Paraná (UFPR), Curitiba, Paraná, Brasil. Email: mcarlaribeiro@uol.com.br
} 


\section{INTRODUÇÃO}

O surgimento e desenvolvimento de aplicativos e serviços em rede que atuam com base na denominada economia do compartilhamento representam um novo fenômeno econômico que desafia os tradicionais mecanismos por meio dos quais busca-se compreender o funcionamento da sociedade. Trata-se de um modo de consumo e circulação de bens e serviços, no qual os agentes econômicos, em vez de procederem à aquisição ou transferência da propriedade dos bens que lhes interessam, preferem alugar, emprestar, ou compartilhar bens entre si. Como consequência, torna mais complexas as reflexões necessárias para o embasamento de proposições adequadas de políticas públicas.

Esse modelo econômico, que privilegia o acesso e usufruto de um bem, em vez da aquisição de sua propriedade, é fomentado e fortalecido pela internet e pelos avanços na tecnologia da informação. Por meio de aplicativos de internet, os usuários das plataformas conseguem trocar, simultaneamente, análises, revisões e avaliações de bens, usuários e serviços, mediante a utilização de tecnologias $\mathrm{p} 2 \mathrm{p}$ (peer-to-peer) que acoplam a oferta e demanda sem a necessidade de intermediários, garantindo a efetividade do sistema.

As facilidades promovidas pela tecnologia da informação permitem uma redução drástica dos custos de transação, fazendo com que muitas pessoas vejam oportunidades de negócios antes impensáveis pelos tradicionais meios de trocas comerciais. Por meio delas, colocam-se em circulação bens e serviços que não seriam negociados, a não ser pela confiança que se deposita no sistema online de compartilhamento.

Todavia há grande apelo de regulação dos serviços que são prestados por meio dessas plataformas, desde a normatização tributária até a de defesa do consumidor. Quanto a este, questiona-se em quê uma regulamentação do setor seria benéfica à população.

Este artigo busca demonstrar de que maneira os aplicativos que atuam com base na economia de compartilhamento corrigem falhas de assimetria informacional, reduzem os problemas da seleção adversa e contribuem para o desenvolvimento econômico e proteção dos consumidores, mesmo na ausência de regulamentação estatal. 


\section{A IMPORTÂNCIA DA ECONOMIA DE COMPARTILHAMENTO}

Como exemplos de plataformas que atuam nesse sistema podemos citar o Fleety, um aplicativo que permite que pessoas aluguem seus carros subutilizados, mediante preços e demais informações pré-estabelecidas; o Airbnb, que permite que seus usuários aluguem suas casas, apartamentos, quartos vagos e, até mesmo, sofás de suas residências para que viajantes possam utilizá-los e o Kickstarster, uma rede no qual milhares de pessoas podem financiar o desenvolvimento de projetos particulares criativos, que vão da gastronomia ao desenvolvimento de games. O aplicativo Uber também inclui-se nessa categoria, ao colocar motoristas particulares e passageiros em contato para a prestação do serviço de carona remunerada.

Os números que envolvem a economia do compartilhamento tem despertado a atenção de investidores, da mídia, da academia e, obviamente, dos seus concorrentes. Para se ter um exemplo, no Rio de Janeiro, existem cerca de 80 mil leitos oferecidos pelo Airbnb, quase o mesmo número oferecido pela hotelaria tradicional (CARRO, 2016). O Kickstarter, por sua vez, já movimentou mais de 2 bilhões de dólares para o financiamento coletivo dos mais variados projetos (KICKSTARTER, 2016). Em Nova York, segundo dados de março de 2015, existiam 14.088 motoristas vinculados ao Uber, número maior que o de 13.587 taxistas da cidade (FOLHA, 2015).

Apesar do grande êxtase na utilização desses serviços pela população, críticas vêm sendo formuladas sobre o seu modo de operação. As greves de taxistas nas grandes cidades, por exemplo, tornaram-se manchete comum nos noticiários internacionais e nos brasileiros. Os taxistas dizem que o Uber é ilegal e representa concorrência desleal para com o serviço de táxis. Com efeito, em junho de 2015, foram presos, em Paris, dois diretores do aplicativo, sob a alegação de que o Uber não respeita as regras previdenciária ou tributárias, além de criar concorrência desleal, que, nas palavras do presidente François Hollande, seria inaceitável e intolerável (HARTMANN, 2016). Os representantes da rede hoteleira têm, em várias ocasiões, requisitado a declaração de ilegalidade da plataforma Airbnb, mediante a invocação de concorrência desleal, dentre outros fundamentos, pelo não pagamento de tributos impostos à rede hoteleira (MENEZES, 2016).

É interessante notar que, quanto ao funcionamento de aplicativos como Uber e Fleety, as instituições governamentais responsáveis pela tutela da concorrência, tais como a entidade mexicana de proteção à concorrência, assim como o Departamento de Estudos 
Econômicos do CADE (2016), vêm se demonstrando favoráveis à utilização dos serviços de "carona remunerada". O argumento é o de que a entrada de novos competidores no mercado de transporte de passageiros poderá trazer benefícios aos consumidores, por meio do acréscimo de concorrência, qualidade do serviço e subsequente diminuição dos preços.

Por outro lado, há um grande apelo para que esse novo modo de relação econômica seja regulado pelo Estado, por razões de justiça fiscal, de concorrência lícita e até de proteção ao consumidor. Contudo, deve-se salientar que as plataformas da economia de compartilhamento exercem, de maneira até mais eficiente que o Estado, o papel de reguladores do mercado em busca da diminuição da assimetria informacional entre os agentes econômicos.

Para atender ao objetivo do presente artigo, recorre-se ao estudo interdisciplinar entre as teorizações sobre economia da informação, regulação econômica e direito do consumidor, além de dados encontrados sobre o funcionamento da economia do compartilhamento diretamente à fonte dos desenvolvedores de aplicativos, ou em matérias jornalísticas.

\section{ASSIMETRIA INFORMACIONAL E SELEÇÃO ADVERSA}

A assimetria informacional é um fenômeno econômico caracterizado pelo fato de uma das partes de uma transação comercial possuir mais informações do que a outra, relativamente ao produto ou serviço que está sendo negociado. Essa diferença de informação gera um desequilíbrio de poder entre as partes, que pode acarretar numa falha de mercado chamada seleção adversa. A identificação desse fenômeno remonta ao célebre artigo de George Akerlof (1970) sobre o "mercado dos limões".

Em seu artigo, Akerlof (1970) demonstra como produtos de melhor qualidade acabam não sendo negociados em vista da assimetria informacional existente entre fornecedores e consumidores. O exemplo tratado pelo autor é o do mercado de carros usados, nos Estados Unidos da América.

Nos Estados Unidos, os carros de má qualidade são também conhecidos como lemons ou limões, enquanto os de boa qualidade são os grapes ou uvas. Quando um consumidor vai ao mercado para comprar um carro, sua última escolha, em princípio, 
recairá sobre um limão, preferindo as uvas. Em outras palavras, um consumidor estaria disposto a pagar mais por uma uva e menos por um limão.

Para melhor entender o problema da seleção adversa, parte-se de uma suposição. Imagine-se que em um determinado mercado de carros usados, existam dois tipos de mercadoria, os limões e as uvas. Os consumidores, em média, estarão dispostos a pagar $\mathrm{R} \$ 15.000,00$ pelos limões e $\mathrm{R} \$ 40.000,00$ pelas uvas. Os vendedores, por sua vez, venderão os limões por $\mathrm{R} \$ 10.000,00$ e as uvas por $\mathrm{R} \$ 30.000,00$.

Se os consumidores tivessem informação completa sobre a qualidade dos veículos à venda, comprariam as uvas pelo preço de venda de $\mathrm{R} \$ 30.000,00$. Porém, ocorre que, neste cenário hipotético, os consumidores não possuem informações suficientes sobre a qualidade dos carros e, neste momento, estão impossibilitados de sabê-lo. Assim, o valor que os consumidores estão dispostos a pagar por qualquer carro usado, já que não sabem quais são os de maior ou menor qualidade, é uma média entre o valor que pagariam por uma uva e por um limão. Na hipótese em comento, o valor médio é de $\mathrm{R} \$ 27.500,00$. Os vendedores, que possuem as informações completas sobre os carros, não venderão as uvas por esse preço. Mas venderiam, com uma grande margem de lucro, os limões. A consequência dessa conjectura é o de que serão negociados apenas os carros usados de baixa qualidade, já que é o preço vantajoso para os detentores da informação completa, mas desvantajoso para os consumidores.

Akerlof (1970) ainda dá mais dois exemplos de como o problema da seleção adversa se manifesta: nos mercados de seguros de saúde e no mercado financeiro. No caso dos seguros de saúde, as seguradoras não tem informação completa sobre a qualidade de vida dos seus potenciais clientes, então acabam estabelecendo preços que não são vantajosos para indivíduos avessos a riscos, ou sadios, firmando a maioria dos contratos com pessoas que com grande probabilidade um dia necessitarão de cirurgias ou outros tratamentos médicos mais caros. No mercado financeiro, sem que as instituições financeiras saibam se um consumidor é bom ou mal pagador, acabam por elevar suas taxas de juro de modo que os bons pagadores decidem por não tomar empréstimos, porque consideram desinteressantes as condições do negócio.

Em suma, em seu trabalho Akerlof (1970) defendeu a tese de que em transações caracterizadas pela assimetria informacional, a parte melhor informada explorará as assimetrias de informação em seu favor. A incerteza sobre a qualidade de um produto, gera 
dificuldades para a realização de transações ótimas, acarretando um abarrotamento de produtos ou contratos de má qualidade no mercado.

Segundo Akerlof (1970), o próprio mercado pode criar instituições e mecanismos de resolução desses problemas, como garantias, marcas, redes e licenças. Aprofundado os estudos nesse sentido, Michael Spence (2001) e Joseph Stigliz (1982) produziram contribuições à ciência econômica, demonstrando como os mecanismos de sinalização e triagem auxiliam na redução da assimetria informacional.

Mediante a sinalização, a parte melhor informada de uma transação toma a iniciativa de demonstrar a outra suas qualidades, ou as qualidades de seu produto. Em seu artigo sobre a sinalização no mercado de trabalho, Spence (2001) demonstra como diplomas, experiência profissional, raça e sexo atuam como sinais aos empregadores das potencialidades do um indivíduo a ser contratado. Produtos e serviços também podem ser sinalizados, mediante a criação de marcas, atestados de qualidade e indicações geográficas. São sinais que levam a parte menos informada de uma transação comercial ao conhecimento de indícios de qualidade do serviço, produto ou do agente econômico a ser contratado.

Por meio da triagem, é a parte menos informada quem toma a iniciativa para a aquisição de informações necessárias a uma boa escolha. Estão compreendidos na triagem instrumentos como questionários, entrevistas e testes, anteriormente à tomada de decisão. Pode ocorrer também de uma empresa disponibilizar ao seu cliente um conjunto de contratos distintos para que este escolha o que melhor lhe convém, ajustando-se à qualidade de informação que detém em face do fornecedor. Esse modelo é cada vez mais comum nos negócios de planos de saúde que fornecem, por exemplo, planos com coparticipação, ou sem coparticipação, visando a uma melhor adequação dos planos à saúde de seus clientes.

Mediante esses mecanismos, as partes tentam evitar a ocorrência da seleção adversa, atuando em busca de informações adequadas sobre as mercadorias, contratos e, inclusive, sobre as qualidades dos demais agentes econômicos disponíveis no mercado.

A contribuição sobre o estudo das assimetrias informacionais desses autores foi significativa, a ponto de que Akerlof, Spence e Stiglitz receberam o Prêmio de Ciências Econômicas em Memória de Alfred Nobel, no ano de 2001. 


\section{ESTADO REGULADOR, ASSIMETRIA INFORMACIONAL E DEFESA DO CONSUMIDOR}

Caso o Estado adote uma política econômica de redução das assimetrias informacionais entre os agentes econômicos, pode se valer do seu poder de criar e editar normas para reduzir os relativos custos de transação. Isso pode ser feito de diversas maneiras, como mediante a criação de uma agência responsável pela qualificação de produtos industriais, de entidades responsáveis pelo registro de marcas e patentes, de instituições responsáveis pela defesa do consumidor, de regras relativas às trocas comerciais (como a obrigação da prestação de informações, ou de estabelecer prazo de garantia), ou, inclusive, pela exigência de certificados ou diplomas para o exercício regulamentar de serviços especializados ou prática profissional.

Um dos principais motivos em defesa da necessidade da regulação estatal com objetivo da redução da assimetria informacional em transações econômicas é o da proteção aos consumidores. Por meio da regulação, os consumidores podem ser protegidos das falhas de mercado, tais como as externalidades negativas, concorrência imperfeita, desigualdade do poder de barganha, assim como pela informação assimétrica.

A Lei ${ }^{\circ}$ 8.078, de 11 de setembro de 1990, o Código de Defesa do Consumidor, representa bem a preocupação do Estado nesse sentido, ao estabelecer em seu art. $4^{\circ}$ os princípios da Política Nacional das Relações de Consumo. Dentre eles destaca-se o incentivo à criação pelos fornecedores de meios eficientes de controle de qualidade e segurança de produtos e serviços. Também relevante o art. $6^{\circ}$ ao prescrever como direito básico do consumidor a informação adequada e clara sobre os diferentes produtos e serviços, com especificação correta de quantidade, características, composição, qualidade, tributos incidentes e preço, bem como sobre os riscos que apresentam.

O Estado brasileiro atua, principalmente, em três vertentes para a redução das assimetrias informacionais entre fornecedores e consumidores: criando ou incentivando a criação de organizações responsáveis pela garantia da qualidade de bens ou serviços; obrigando os fornecedores a disponibilizar informações necessárias para a comercialização de produtos; e reprimindo condutas potencialmente lesivas ao consumidor.

Os táxis e os hotéis, para a finalidade deste artigo, são bons exemplos para demonstrar a maneira pela qual o Estado atua, regulamentando tais serviços na busca da redução da assimetria informacional. 
Por meio da regulação, o Estado pode exigir da prestação do serviço de táxi uma série de requisitos: que o motorista deve possuir uma determinada habilitação para dirigir; determinado tempo mínimo de experiência enquanto motorista; uma pintura específica para o veículo; um emplacamento diferenciado; regras para o transporte de passageiros e bagagens; a necessidade de utilização do taxímetro. Trata-se do fenômeno da sinalização, teorizado por Michael Spence (2001). Desse modo, quando um consumidor avista um táxi, não tem dúvidas de que, realmente, trata-se de um táxi e não de um veículo dirigido por um motorista qualquer. O custo para encontrar um veículo para seu transporte individual é diminuído. Além disso, o consumidor tem alguma noção de qual será o preço cobrado pela viagem, tendo em vista a utilização do taxímetro.

Quanto aos hotéis, existem uma série de regulamentações, como o registro do hotel no setor competente, a exigência de vistorias periódicas da vigilância sanitária, a responsabilização objetiva pela segurança dos hóspedes, determinação da quantidade de ruído que pode ser produzido pelo estabelecimento, a proibição de fumar nos ambientes internos, etc. Essas regras criam uma padronização dos serviços de hotelaria, de modo que os consumidores têm uma noção mínima dos seus direitos e do que esperar quando firmar um contrato de hospedagem com um hotel.

Contudo, mesmo com essa intervenção intensa do Estado nas relações comerciais e na entrada de agentes econômicos no mercado, nem toda a assimetria informacional é reduzida. Ainda há casos em que ela se manifesta apesar da regulação.

O primeiro motivo para isso é o de que a observância da regulação, pelos agentes econômicos regulados, depende também da existência da fiscalização pelo ente estatal. Normas sem fiscalização tendem a não ser socialmente eficazes. Cooter e Ulen (2012) reforçam esse argumento ao demonstrarem que a obediência às normas não decorre, tão somente, da sua validade, mas também de dois outros elementos: a severidade da sanção derivada da desobediência à norma; e a probabilidade de ser pego. Justamente esse segundo elemento exige o dispêndio de recursos pelo Estado na fiscalização dos indivíduos submetidos às leis. Esses recursos não são apenas monetários, mas também exigem tempo, servidores e toda uma burocracia especializada na norma a ser aplicada. Quanto maior a regulamentação existente, maior será o custo da fiscalização. Em locais com intenso fluxo de turistas, ou em casos de grandes eventos de entretenimento, por exemplo, é comum que taxistas não utilizem o taxímetro e cobrem um valor demasiadamente superior ao que 
deveria ser cobrado para a realização de uma viagem (ARAUJO, 2016). Isso ocorre porque não há alocação de recursos suficientes para a fiscalização nesses momentos ou locais.

O segundo motivo é o de que a regulação, por mais extensa que seja, não consegue dar conta de todas as nuances existentes nas relações comerciais. Se o consumidor não conhece de antemão o trajeto mais curto para um deslocamento, ficará à mercê do taxista, que poderá fazer um caminho mais longo para que receba mais pela travessia do trecho.

O terceiro motivo prevalece quando as organizações responsáveis pela proteção dos consumidores são ineficazes e ineficientes para a consecução de seus objetivos. As multas aplicadas pelos órgãos de defesa do consumidor podem ser discutidas judicialmente e postergadas até o fim do trânsito em julgado. Ademais, os procedimentos realizados pelo Procon exigem a presença das partes e realizações de audiências de conciliação que não são vantajosas economicamente a nenhuma das partes. Como resultado, o sistema de proteção estatal aos consumidores é lento e ineficiente.

Devem ser consideradas ainda as falhas do sistema em relação à proteção dos fornecedores de bens ou serviços. Por exemplo, um taxista nem sempre sabe se a pessoa que transportará é um bom cliente ou um assaltante.

Esses problemas, na economia de compartilhamento, são reduzidos, por causa dos custos reduzidos para aquisição de informação, por meio de mecanismos de sinalização, triagem e avaliação de reputação de produtos, serviços e usuários, que funcionam pela troca de informações da internet.

\section{A REDUÇÃO DAS ASSIMETRIAS INFORMACIONAIS NA ECONOMIA DO COMPARTILHAMENTO}

O papel que a confiança e a reputação exercem na cooperação social e nas trocas comerciais sempre foi importante para o desenvolvimento econômico. Axelrod (1984) em célebre estudo sobre a cooperação social, tendo como marco teórico a teoria dos jogos, aduziu que a reputação de um jogador reside na crença sobre qual estratégia outro jogador adotará.

Em termos mais simples, um jogador adotará posturas diferentes se souber de antemão a reputação do outro jogador. Isso é de importância fundamental para a compreensão do funcionamento da sociedade e do mercado, pois é o conhecimento da 
reputação de outrem que facilita a iniciativa na tomada de decisões, incluindo-se as transações comerciais. Assim, na lógica comercial, a boa reputação é fundamental para que novos clientes se sintam seguros para a realização de trocas comerciais com os comerciantes.

Várias formas de mecanismos de reputação já foram desenvolvidas para que as pessoas se informem mais adequadamente, para realizar juízos das outras pessoas, empresas ou mercadorias, para que, ao fim, tomassem melhores decisões. Os custos para aquisição de informação sobre produtos ou serviços, por exemplo, são diminuídos quando se conhece a reputação de uma empresa, pelo reconhecimento da marca, notícias ou relatos de amigos.

A reputação age como um incentivo tanto para constranger comportamentos oportunistas, caso dos free-riders, assim como para incentivar agentes honestos. A reputação age como uma instituição informal, segundo as teorias de Douglass North (1991) e Oliver Williamson (1985), ou seja, como uma complexidade de valores, normas, crenças, símbolos e costumes socialmente apreendidos e compartilhamentos, que definem o comportamento esperado e aceito numa realidade social.

Antes da internet, as reputações se fïrmavam pela comunicação direta dos agentes, por meio de rumores, ou por veículos de comunicação em massa. Contudo, com o surgimento do comércio via internet, os custos de transação relativos à aquisição de informação diminuíram intensamente. Por meio de sites de vendas de itens usados é possível saber quantos negócios já foram realizados por determinado fornecedor, quais delas foram bem- sucedidas, quais não foram, motivos de reclamação, se os bens foram entregues em ótimo estado, se há resposta aos questionamentos, e assim por diante.

Os desenvolvimentos tecnológicos induzem as companhias a se tornarem mais preocupadas com as demandas dos consumidores. Muitas empresas possuem páginas oficiais em redes sociais, como o Facebook e o Twitter, destinados para responder às solicitações dos consumidores.

A economia do compartilhamento tem criado, ou aprimorado, mecanismos de reputação, adaptando-os às mudanças tecnológicas, baseados em dois modelos principais: o modelo centralizado de reputação e o modelo $p 2 p$ (peer-to-peer, literalmente de pessoa-apessoa).

O modelo centralizado de reputação reside na reputação da plataforma online em si e nas garantias que ela oferece aos usuários do seu aplicativo. Funciona com base em 
armazenamento de informações existentes em seus bancos de dados e em sua rápida capacidade de análise e processamento. Geralmente quando o aplicativo lucra mediante a cobrança de porcentagem do negócio realizado, há o modelo centralizado de reputação. $\mathrm{O}$ Airbnb, que cobra uma porcentagem do preço das estadias, oferece aos fornecedores dos leitos um seguro de até um milhão de dólares contra imprevistos, danos físicos à propriedade ou reclamação de terceiros (AIRBNB, 2016). O Uber exige dos seus motoristas a comprovação de que possuem licença para dirigir, além de certos requisitos no veículo, como cor e nível de conforto (UBER, 2016).

O segundo modelo é o mecanismo peer-to-peer. Trata-se de mecanismo no qual os consumidores avaliam a qualidade do produto ou serviço após utilizá-lo, ou mesmo as qualidades do seu fornecedor. Os aplicativos mais recentes da economia do compartilhamento tem aberto a oportunidade para que os fornecedores também avaliem os consumidores.

Essas avaliações podem se dar de diversas maneiras, desde simples marcações baseados em estrelas, que normalmente vão de uma estrela a cinco estrelas, até análises escritas mais detalhadas sobre todas as nuances de um negócio realizado. Assim, um motorista do Lyft ou Uber pode saber de antemão se um potencial cliente já utilizou do serviço de carona remunerada anteriormente, se efetivou o pagamento, se foi desrespeitoso, e vice-versa. O mesmo para as pessoas que disponibilizam seus quartos ou apartamentos vagos sobre eventuais viajantes que pretendam utilizá-los.

O economista David D. Friedman (2008) sustenta que há um reputational enforcement que funciona mediante a dispersão de informações verdadeiras sobre maus comportamentos. As pessoas que recebem essas informações modificarão suas ações com base nelas, o que cria custos sobre aqueles que se comportam mal.

A construção de reputação online na economia do compartilhamento não difere muito da construção da reputação do mundo físico, quanto ao fato de que está centrada no estabelecimento de comunicação e reconhecimento entre seres humanos. O diferencial está na quase inexistência de custos para a aquisição das informações necessárias e na facilidade da disponibilização de bens ou oferecimento de serviços.

A economia do compartilhamento reúne as informações dispersas dos seus usuários, o que gera um certo equilíbrio entre fornecedores e consumidores. Esses sistemas permitem que seus usuários provejam informações instantâneas sobre os produtos e serviços que estão 
utilizando, aumentando a qualidade da informação dos futuros usuários, num ciclo poderoso de transferência de dados muito distinto das soluções tradicionais de resolução das assimetrias informacionais.

A quantidade e qualidade de revisões e avaliações realizadas pelos usuários dos aplicativos da economia do compartilhamento funcionam como um sinalizador, aos usuários futuros, da efetividade do sistema. Ainda, muitos aplicativos se utilizam da triagem para a realização de serviços mais adequados entre os seus usuários. $\mathrm{O}$ aplicativo Uber, por exemplo, disponibiliza tanto a função Uber Black, mais cara mas com carros de maior conforto e luxo, como o Uber $X$, mais acessível e com carros menos sofisticados, mas ainda de grande conforto.

\section{ESPAÇO PARA A REGULAÇÃO DA ECONOMIA DO COMPARTILHAMENTO}

Em vista do que até agora foi exposto, resta claro que os aplicativos da economia do compartilhamento reduzem drasticamente a assimetria informacional, mesmo na ausência de regulação estatal. Um usuário é capaz de saber de antemão as características de um serviço que lhe será prestado e a quantia que será paga. Trajetos são definidos antecipadamente, a qualidade de apartamentos, restaurantes e hotéis são asseguradas por relatos de experiências de outros usuários, e quebras de confiança no sistema de reputação são severamente penalizadas. Além disso, a maior parte das transações na economia do compartilhamento são realizadas mediante cartão de crédito, o que aumenta a segurança dos usuários e dificulta comportamentos oportunistas, já que o cancelamento de cobranças em cartão de crédito são razoavelmente acessíveis.

Ainda assim, tanto tomadores de decisões políticas, como os setores tradicionais do comércio, argumentam que a economia do compartilhamento é injusta porque evade as regulações aplicáveis ao setor tradicional, tais como licenças, controle de preços, requisitos técnicos, e padrões tecnológicos.

Muito se discute pela necessidade da aplicação, ou não, do Código de Defesa do Consumidor às relações negociais travadas mediante economia do compartilhamento. A questão nodal é saber se indivíduos que compartilham seus bens, ou serviços, podem ser enquadrados no conceito de fornecedor do CDC. Como salientado por Claudia Lima Marques e Bruno Miragem (2015) 
Deve-se perguntar se podem ser caracterizados como relações de consumo aquelas estabelecidas entre quem deseja contratar a utilização e o outro que oferece e compartilha o uso de um bem, mesmo não sendo um empresário ou profissional que realize a atividade de modo organizado. Ou ainda, situações já conhecidas de pessoas comuns que se utilizam de modo espontâneo e eventual, da internet para vender coisas usadas. A rigor, estas situações em que não está presente uma organização profissional, ou exercício habitual da atividade para a obtenção do lucro, não se consideram relações de consumo.

Como o CDC preceitua que fornecedor é toda pessoa que desenvolve atividade de produção, montagem, criação, construção, transformação, importação, exportação, distribuição ou comercialização de produtos ou prestação de serviços, e as plataformas online de compartilhamento apenas facilitam a realização dessas trocas comerciais, a aplicação do CDC ao novo sistema fica, em princípio, prejudicada.

A aplicação das disposições consumeristas à economia do compartilhamento deveria, primeiramente, suplantar esse empecilho, mediante uma mudança legislativa no conceito de fornecedor para os fins da aplicação do Código de Defesa do Consumidor. Tal mudança, porém, em termos de política do direito no processo de formação das normas jurídicas, deveria sopesar os custos e benefícios da aplicabilidade do CDC às relações travadas mediante economia do compartilhamento. Sabendo que poderão ser sancionadas pelas disposições da legislação de defesa do consumidor, muitos usuários poderão se afastar da utilização dos aplicativos.

Para além dessa questão é importante apontar que o funcionamento da economia do compartilhamento não ocorre, necessariamente, em desrespeito à defesa do consumidor. Veja-se que, mesmo que o CDC não incida sobre a utilização e funcionamento dos aplicativos de economia do compartilhamento, o seu maior trunfo reside na segurança e na qualidade da informação que é disponibilizada aos seus usuários.

Especulando sobre um cenário no qual inexistam proteções legais aos consumidores, como partes hipossuficientes de negócios jurídicos, Ben-Shahar (2010) sugere que o próprio mercado daria surgimento a mecanismos e instrumentos de proteção ao consumidor, tendo em vista a necessidade de atendimento aos anseios consumeristas para um melhor desempenho empresarial.

Segundo Ben-Shahar (2010), proteções não-jurídicas emergiriam. Em primeiro lugar, novos modelos contratuais se estabeleceriam, de modo a assegurar, por exemplo, 
que o consumidor pudesse sair a qualquer momento do negócio, sem a necessidade de pagamento de multas escondidas em cláusulas complexas. Em segundo lugar, garantias seriam criadas para assegurar os consumidores contra fornecimento de bens ou serviços mal realizados. Em terceiro lugar, seguros seriam criados e disponibilizados aos consumidores para auxiliá-los contra a má prestação de serviços. Em quarto lugar, na ausência de proteção legal, os consumidores teriam que se embasar na reputação das empresas que contratam, criando plataformas de reputação para onde os consumidores pesquisariam o histórico das empresas. Em quinto, e último, os fornecedores teriam que ir além do que a lei geralmente obriga, fornecendo mais regalias aos consumidores.

Independente da plausibilidade de seus argumentos quanto aos setores tradicionais do comércio e da indústria, a teorização de Ben-Shahar (2010) parece relatar a situação na qual atuam os atuais aplicativos da economia do compartilhamento. Os modelos contratuais são de fácil adesão, mas também muito simples de se realizar o seu destrato. Não existem multas a serem pagas pela desinstalação do aplicativo, ou do cancelamento dos negócios, realizados dentro de um prazo razoável. Como já mencionado, o Airbnb tem fornecido seguros contra imprevistos e mal comportamento de viajantes. Motoristas do Uber oferecem serviços não obrigatórios aos caroneiros, para aumento do seu conforto. E, por fim, a reputação dos agentes envolvidos é a base que dá confiança a todo o sistema.

Portanto, é necessário notar que as situações de mercado mudaram de maneira significativa. Os serviços prestados pela economia do compartilhamento não são os mesmos dos serviços tradicionais. Tentativas de aplicação de regulações antiquadas a novas invenções podem ter resultados economicamente ineficientes. Veja-se que, mesmo na ausência de regulamentação, muitos consumidores preferem a utilização do Uber ao serviço tradicional dos táxis. Os números de hospedagem via Airbnb aumentam exponencialmente também na ausência de regulamentação. Financiamentos coletivos, via Kickstarter, são feitos sem a regulação de um banco central, ou resoluções de instituições financeiras.

Os problemas regulatórios que surgem quanto à utilização da economia do compartilhamento estão muito mais ligados a problemas estatais de arrecadação tributária e formação de políticas públicas. Não existem critérios objetivos e pacíficos para a tributação de corridas realizadas pelo Uber, de hospedagens via Airbnb, ou 
investimentos via Kickstarter. Ainda, o Estado não tem acesso a todos os dados de funcionamento desses aplicativos, justamente por serem dados privados e não públicos. Ainda, vem se afirmando que a ausência de tributação e exigências específicas ao setor da economia do compartilhamento criou uma situação de concorrência desleal com os setores tradicionais. Porém, não há sentido em punir novas inovações aplicando regulações antigas para tecnologias e modos de circulação de bens e serviços inovadores.

Ao contrário, para nivelar concorrencialmente a economia do compartilhamento com os setores tradicionais, seria interessante promover a própria desregulamentação desta, verificando quais requisitos ainda fazem sentido no moderno mundo da tecnologia da informação em que se vive. Esse é, aliás, o recente posicionamento da Secretaria de Acompanhamento Econômico do Ministério da Fazenda (2016), que, em análise dos impactos concorrenciais da introdução do aplicativo Uber no Mercado Relevante de Transporte Individual de Passageiros, aduziu que:

O fato de que um serviço novo (Uber) - integrante do mercado relevante de transporte individual de passageiros - cresce e conquista novos consumidores a cada dia, sem que qualquer regulamentação tenha sido necessária para que os consumidores se sentisse confiantes em aderir a esse novo serviço, coloca em questão a regulamentação desse serviço, bem como dos serviços tradicionais de táxi. [...]

Parte dos problemas que a regulação dos serviços de táxi busca mitigar são endereçados pelos aplicativos, conferindo, potencialmente, maior grau de satisfação aos usuários do serviço de transporte individual de passageiros.

[...]

Assim, a redução do custo de obter informações e as facilidades de seu acesso possibilitado pelas inovações tecnológicas endereçam questões que estão presentes na regulação do serviço de táxi, de forma que parte das preocupações que ensejaram regulamentações mais densas naquele mercado não possui mais a mesma importância ou poderiam ser resolvidas de forma mais eficiente de outra maneira.

Em relação ao Uber, esta Seae entende que a regulação caso necessária deva ser mínima, não podendo criar barreiras que inviabilizem o modelo de operação dos aplicativos junto aos prestadores de serviço AVP. [...]

Conclui-se, portanto, que existe necessidade de desregulamentação dos serviços de táxi, até como resultado da incorporação das inovações trazidas pelos aplicativos para o mercado de transporte individual de passageiros.

Deve-se, portanto, analisar com ceticismo os argumentos de que as propostas de regulação da economia do compartilhamento tem, como objetivo primordial, a proteção dos interesses do consumidor. Afinal, muitos dos problemas que levaram à criação do Código de Defesa do Consumidor inexistem nas relações travadas entre usuários de plataformas da economia do compartilhamento, especialmente no que se refere ao tratamento de sua hipossuficiência decorrente da assimetria informacional entre consumidor e fornecedor. 


\section{CONCLUSÃO}

As regulações econômicas em busca do equilíbrio informacional entre consumidores e fornecedores de bens ou serviços desempenham um papel importante no desenvolvimento econômico e na defesa do consumidor, nos cenários em que o custo para aquisição de informações necessárias para a realização de transações comerciais é elevado. O Código de Defesa do Consumidor tem, como um de seus objetivos, justamente o de garantir o acesso à informação aos consumidores dos serviços e produtos que consomem junto aos respectivos fornecedores.

O desenvolvimento de aplicativos online de avaliações da qualidade de bens e serviços, assim como de reputação de empresas e indivíduos, resultou em um robusto modelo econômico, cada vez mais utilizado pela sociedade, denominado economia do compartilhamento, que fornece mecanismos eficientes de proteção ao consumidor, tão ou mais efetivos do que aqueles previstos legalmente pelo poder público.

A aplicação de regulações antiquadas para esse novo modo de se fazer economia pode significar a impossibilidade de funcionamento de aplicativos da economia do compartilhamento no mercado brasileiro, o que será economicamente ineficiente além de representar uma queda no nível de bem-estar dos consumidores, já que estes utilizam cada vez mais seus serviços na ausência de regulamentação estatal.

Relativamente à proteção ao consumidor, pouco há a se regular na economia do compartilhamento, uma vez que a assimetria informacional entre fornecedores e consumidores, nesta seara, tornou-se praticamente inexistente e qualquer abuso cometido por um usuário é prontamente penalizado pelo próprio aplicativo, mediante sistemas online de reputação.

Cabe ao Estado promover, se for de seu interesse, as regulações econômicas de cunho tributário ou atinente a diversas políticas públicas, mas que pouco tem a ver com a redução de assimetrias de informação entre os agentes econômicos para o bom funcionamento do mercado.

Os mecanismos autorregulatórios dos serviços da economia do compartilhamento vem demonstrando que são eficazes para a proteção ao consumidor, 
em comparação àqueles criados e mantidos pelo poder público. Isso porque a busca do lucro, dependente de sistemas online de reputação, é muito mais poderosa para assegurar a qualidade de atendimento e da prestação de serviços, do que as determinações legais.

\section{REFERÊNCIAS BIBLIOGRÁFICAS}

AKERLOF, George A. The Market for "Lemons": Quality Uncertainty and the Market Mechanism. Disponível em: http://links.jstor.org/sici?sici=0033$5533 \% 28197008 \% 2984 \% 3 \mathrm{a} 3 \% 3 \mathrm{c} 488 \% 3 \mathrm{atmf} \% 22 \mathrm{qu} \% 3 \mathrm{e} 2.0 . \mathrm{co} \% 3 \mathrm{~b} 2-6$ Acesso em 21 de dezembro de 2015.

ARAUJO, Isabel de. Taxistas cobram ilegalmente até $40 \%$ a mais para atravessar a Ponte. Jornal O Globo. Disponível em http://extra.globo.com/noticias/rio/taxistas-cobram-ilegalmenteate-40-mais-para- atravessar-ponte-7595206.html Acesso em: 07 de janeiro de 2016.

Cf. Jornal O Dia. Passageiros denunciam taxistas que cobram a mais pelas corridas. Mai. 2014. Disponível em: http://odia.ig.com.br/noticia/rio-de- janeiro/2014-05-19/passageirosdenunciam-taxistas-que-cobram-a-mais-pelas-corridas.html Acesso em: 07 de janeiro de 2016.

ROCHA, S. Taxistas ignoram taxímetro e cobram mais caro pelas corridas. Jul. 2013. Disponível em: http://sergiorochareporter.com.br/taxistas-ignoram-taximetro-e-cobram-maiscaro-pelas- corridas/ Acesso em: 07 de janeiro de 2016.

AXELROD, Robert. The Evolution of Cooperation. Nova York: Basic Books, 1984.

BEN-SHAHAR, Omri. One-Way Contracts: Consumer Protection Without Law. 6 European Review of Contract Law 221, 2010.

BRASIL. Ministério da Fazenda. Secretaria de Acompanhamento Econômico. Nota Técnica $n^{o}$ 06013/2016/DF/COGUN/SEAE/MF. Fev. 2016. Disponível em: http://www.seae.fazenda.gov.br/assuntos/advocacia-da-concorrencia/notas-tecnicas/2016/notatecnica-n-o-06013-2016-df-impactos-concorrenciais-do-uber-no-mercado- relevante-detransporte-individual-de-passageiros.pdf Acesso em 15 de fevereiro de 2016.

CADE. DEPARTAMENTO DE ESTUDOS ECONÔMICOS. O mercado de transporte individual de passageiros: regulação, externalidades e equilíbrio urbano. Set. 2015. 
Disponível

em:

http://www.cade.gov.br/upload/O\%20Mercado\%20de\%20Transporte\%20Individual\%20de $\% 20$

Passageiros.pdf Acesso em: 09 de janeiro de 2016.

CARRO, R. Airbnb avança sem resistência no mercado. Brasil Econômico. Jun. 2015. Disponível em: http://brasileconomico.ig.com.br/negocios/2015-06-22/airbnb-avanca-semresistencia-no-mercado.html Acesso em: 07 de janeiro de 2016.

COHEN, Molly; SUNDARARAJAN, Arun. Self-Regulation and Innovation in the Peer-toPeer Sharing Economy. Disponível em: https://lawreview.uchicago.edu/sites/lawreview.uchicago.edu/files/uploads/Dialogue/Sundar arajan_Cohen_Dialogue.pdf Acesso em 22 de dezembro de 2015.

COOTER, ULEN. Law \& Economics. 6th ed. Boston: Pearson, 2012.

FOLHA DE SÃO PAULO. Carros do Uber superam número de táxis em NY; Alemanha proíbe app. Mar. 2015. Disponível em: http://www1.folha.uol.com.br/tec/2015/03/1605069-carros-douber-superam-numero-de-taxis-em-ny-alemanha-proibe-app.shtml Acesso em: 07 de janeiro de 2016.

FRIEDMAN, David D. Future Imperfect: Technology and Freedom in an Uncertain World. Cambridge: Cambridge University Press, 2008.

HARTMANN, C. Diretores do Uber são presos em Paris; entenda por que o serviço é ilegal. RFI Brasil. Jun. 2015. Disponível em: http://br.rfi.fr/franca/20150629-diretores-do-uber-saopresos-em-paris- entenda-por-que-o-servico-e-ilegal Acesso em: 07 de janeiro de 2016.

KICKSTARTER. Stats. Disponível em: https://www.kickstarter.com/help/stats Acesso em: 07 de janeiro de 2016.

KOOPMAN, Christopher; MITCHELL, Matthew; THIERER, Adam. The Sharing Economy and Consumer Protection Regulation: The Case for Policy Change. Disponível em: http://mercatus.org/publications/sharing-economy-and-consumer-protection-regulation-casepolicy-change. Acesso em 21 de dezembro de 2015. 
MENEZES, P. ABIH-RJ critica Airbnb e avisa: "hotelaria investiu R\$12 bi em 2015". Mercado \& Eventos. Nov. 2015. Disponível em: http://www.mercadoeeventos.com.br/site/noticias/view/123650/abih-rj- critica-airbnb-e-avisahotelaria-investiu-12-bi-em-2015 Acesso em: 08 de janeiro de 2016.

MIRAGEM, Bruno; MARQUES, Claudia L. Economia do compartilhamento deve respeitar direitos do consumidor. In: Revista Consultor Jurídico. Dez. 2015. Disponível em: http://www.conjur.com.br/2015-dez-23/garantias-consumo-economia-compartilhamentorespeitar-direitos-consumidor Acesso em: 14 de janeiro de 2016.

NORTH. Douglass C. Institutions. In: The Journal of Economic Perspectives. Vol. 5. No. 1. Disponível em: $\quad$ http://links.jstor.org/sici?sici=0895$3309 \% 28199124 \% 295 \% 3 \mathrm{~A} 1 \% 3 \mathrm{C} 97 \% 3 \mathrm{AI} \% 3 \mathrm{E} 2.0 . \mathrm{CO} \% 3 \mathrm{~B} 2-\mathrm{W}$

NORTH, Douglass C. Institutions, Institutional Change and Economic Performance. Cambridge: Cambridge University Press, 1990.

SPENCE, Michael. Signaling in retrospect and the informational structure of markets. Disponível em: $\quad$ http://www.nobelprize.org/nobel_prizes/economicsciences/laureates/2001/spence-lecture.pdf Acesso em 05 de janeiro de 2016.

STIGLITZ, Joseph E. Information, Screening, and welfare. Disponível em: https://www.princeton.edu/ erp/ERParchives/archivepdfs/M302.pdf Acesso em 05 de janeiro de 2016.

WILLIAMSON, Oliver E. The Economic Institutions of Capitalism: Firms, Markets, Relational Contracting. Nova Iorque: The Free Press, 1985. 